University of Nebraska - Lincoln

DigitalCommons@University of Nebraska - Lincoln

Faculty Papers and Publications in Animal

Science

Animal Science Department

January 2004

\title{
Covariance functions and random regression models for cow weight in beef cattle
}

Jesus Arango

University of Nebraska-Lincoln, jarango2@unl.edu

L. V. Cundiff

USDA, ARS, Roman L. Hruska U.S. Meat Animal Research Center

L. Dale Van Vleck

University of Nebraska-Lincoln, dvan-vleck1@unl.edu

Follow this and additional works at: https://digitalcommons.unl.edu/animalscifacpub

Part of the Animal Sciences Commons

Arango, Jesus; Cundiff, L. V.; and Van Vleck, L. Dale, "Covariance functions and random regression models for cow weight in beef cattle" (2004). Faculty Papers and Publications in Animal Science. 202.

https://digitalcommons.unl.edu/animalscifacpub/202

This Article is brought to you for free and open access by the Animal Science Department at DigitalCommons@University of Nebraska - Lincoln. It has been accepted for inclusion in Faculty Papers and Publications in Animal Science by an authorized administrator of DigitalCommons@University of Nebraska - Lincoln. 


\title{
Covariance functions and random regression models for cow weight in beef cattle ${ }^{1}$
}

\author{
J. A. Arango*2, L. V. Cundiff $\dagger$, and L. D. Van Vleck $\ddagger^{3}$ \\ *Department of Animal Science, University of Nebraska, Lincoln 68583-0908, and USDA, ARS, Roman L. \\ Hruska U.S. Meat Animal Research Center, †Clay Center, NE 68933, and $\ddagger$ Lincoln, NE 68583-0909
}

\begin{abstract}
Data from the first four cycles of the Germplasm Evaluation program at the U.S. Meat Animal Research Center were used to evaluate weights of Angus, Hereford, and $\mathrm{F}_{1}$ cows produced by crosses of 22 sire and 2 dam (Angus and Hereford) breeds. Four weights per year were available for cows from 2 through $8 \mathrm{yr}$ of age (AY) with age in months (AM). Weights (n $=61,798)$ were analyzed with REML using covariance function-random regression models (CF-RRM), with regression on orthogonal (Legendre) polynomials of AM. Models included fixed regression on AM and effects of cow line, age in years, season of measurement, and their interactions; year of birth; and pregnancy-lactation codes. Random parts of the models fitted RRM coefficients for additive (a) and permanent environmental (c) effects. Estimates of CF were used to estimate covariances among all ages. Temporary environmental effects were modeled to account for heterogeneity of
\end{abstract}

variance by AY. Quadratic fixed regression was sufficient to model population trajectory and was fitted in all analyses. Other models varied order of fit and rank of coefficients for a and c. A parsimonious model included linear and quartic regression coefficients for a and c, respectively. A reduced cubic order sufficed for c. Estimates of all variances increased with age. Estimates for older ages disagreed with estimates using traditional bivariate models. Plots of covariances for $\mathrm{c}$ were smooth for intermediate, but erratic for extreme ages. Heritability estimates ranged from 0.38 (36 mo) to 0.78 (94 $\mathrm{mo}$ ), with fluctuations especially for extreme ages. Estimates of genetic correlations were high for most pairs of ages, with the lowest estimate $(0.70)$ between extreme ages (19 and $103 \mathrm{mo}$ ). Results suggest that although cow weights do not fit a repeatability model with constant variances as well as CF-RRM, a repeatability model might be an acceptable approximation for prediction of additive genetic effects.

Key Words: Mature Weight, Growth, Genetic Parameters, Beef Cattle

(C2004 American Society of Animal Science. All rights reserved.

J. Anim. Sci. 2004. 82:54-67

\section{Introduction}

The importance of body size to efficiency has led to selection for variables associated with mature weight. Body size or growth can be represented by a set of sizeage points that gradually change until reaching a plateau at maturity. These points represent a set of many highly correlated measures. The challenge is to condense the data points for an animal into a manageable set of parameters with biological meaning. Several approaches

\footnotetext{
${ }^{1}$ Published as Paper No. 14030, Journal Ser., Nebraska Agric. Res. Div., Univ. of Nebraska, Lincoln 68583-0908.

${ }^{2}$ Current address: Facultad de Ciencias Veterinarias, Universidad Central de Venezuela, Apartado 4563, Maracay 2101, Aragua, Venezuela.

${ }^{3}$ Correspondence: A218 Animal Sciences, Univ. of Nebraska, Lincoln (phone: 402-472-6010; fax: 402-472-6362; e-mail: dvan-vleck1@ unl.edu).

Received March 13, 2003.

Accepted August 20, 2003.
}

have been proposed, from a simple repeatability model to a full multivariate model. Intermediate alternatives include traditional "growth functions," which explain the growth trajectory using a few parameters defined by a deterministic equation. A recent approach has been to use covariance functions (CF, Kirkpatrick and Heckman, 1989) and random regression models (RRM, Henderson, Jr., 1982; Schaeffer and Dekkers, 1994). The equivalence of $\mathrm{CF}$ and RRM has been described (e.g., Meyer and Hill, 1997; van der Werf et al., 1998). Under this framework, infinite-dimensional stochastic models have been proposed with the phenotype represented as a continuous function of time. The covariance between two measurements is defined as a function of the ages and some basic coefficients. Orthogonal polynomials (e.g., Legendre polynomials) are often used to represent coefficients for the RRM, assuming that the trajectory can be described by such polynomials. The main requirement for the model is that the time-dependent response can be expressed as a function of a set of covariates (Schaeffer and Dekkers, 1994). 
Table 1. Number of sires (cows) by breed of sire for Cycles I to IV of the GPE Program

\begin{tabular}{|c|c|c|c|c|}
\hline Breed of sire & $\begin{array}{l}\text { Cycle I } \\
\text { (1970 to 1972) }\end{array}$ & $\begin{array}{l}\text { Cycle II } \\
\text { (1973 to 1974) }\end{array}$ & $\begin{array}{l}\text { Cycle III } \\
\text { (1975 to 1976) }\end{array}$ & $\begin{array}{l}\text { Cycle IV } \\
\text { (1986 to } 1990)\end{array}$ \\
\hline Hereford $^{\mathrm{ab}}$ & $31(121)$ & $15(86)$ & $13(68)$ & 48 (169) \\
\hline Angus $^{\mathrm{ab}}$ & $33(123)$ & $17(92)$ & $14(30)$ & 49 (164) \\
\hline Jersey & 32 (106) & & & \\
\hline South Devon & 27 (109) & & & \\
\hline Simmental & $27(151)$ & & & \\
\hline Limousin & $20(148)$ & & & \\
\hline Charolais $^{b}$ & $26(123)$ & & & $32(82)$ \\
\hline Red Poll & & $16(87)$ & & \\
\hline Brown Swiss & & $11(127)$ & & \\
\hline Maine Anjou & & $17(86)$ & & \\
\hline Chianina & & $19(86)$ & & \\
\hline Gelbvieh $^{b}$ & & $11(77)$ & & $16(76)$ \\
\hline Brahman & & & $17(101)$ & \\
\hline Sahiwal & & & $6(86)$ & \\
\hline Pinzgauer $^{\mathrm{b}}$ & & & $9(103)$ & $15(81)$ \\
\hline Tarentaise & & & $6(80)$ & \\
\hline Shorthorn & & & & $22(69)$ \\
\hline Galloway & & & & $27(70)$ \\
\hline Longhorn & & & & $24(81)$ \\
\hline Nellore & & & & $22(81)$ \\
\hline Piedmontese & & & & $18(83)$ \\
\hline Salers & & & & $25(86)$ \\
\hline Total & $196(881)$ & $106(641)$ & 65 (468) & $298(1,042)$ \\
\hline
\end{tabular}

${ }^{a}$ Hereford and Angus reference sires, originally sampled in 1969, 1970, and 1971, were used in all cycles.

${ }^{\mathrm{b}}$ Hereford, Angus, Charolais, Gelbvieh, and Pinzgauer sires born after January 1982 were used in Cycle IV in addition to the original Hereford and Angus reference sires.

This paper presents estimates of genetic and phenotypic parameters using the CF-RRM approach for cow weights from the first four cycles of the Germplasm Evaluation Program, at the U.S. Meat Animal Research Center. Previous reports presented parameter estimates for cow traits as summarized by Arango et al. (2002); however, this is the first study that uses the CF-RRM in analysis of data from the evaluation program populations.

\section{Materials and Methods}

\section{Data}

Data from the first four cycles of Germplasm Evaluation Program included weights of purebred Angus and Hereford cows (Cycles I, II, and IV) and crossbred cows (all cycles) produced by mating Angus and Hereford dams to 22 breeds of sire. The breeds, numbers of sires, and cows by breed of sire for each cycle are in Table 1 . Hereford-Angus reciprocal crosses were produced in each cycle. Some Angus and Hereford sires used in Cycle I were repeated as reference sires in following cycles to provide genetic ties across all cycles. Cycle I began with the 1969 breeding season, with matings through artificial insemination (AI) of Hereford, Angus, Jersey, South Devon, Limousin, Simmental, and Charolais bulls to Hereford and Angus cows. Calves were born in March, April, and early May of 1970, 1971, and 1972. Cycle II included two calving seasons (1973 and 1974). Hereford and Angus cows from Cycle I were bred by AI to Hereford,
Angus, Braunvieh, Red Poll, Maine Anjou, Gelbvieh, and Chianina bulls. Cycle III was initiated with Angus and Hereford cows from Cycles I and II during the 1974 breeding season when they were bred by AI to Hereford, Angus, Pinzgauer, Tarentaise, Brahman, and Sahiwal sires to produce crossbred calves in two calving seasons (1975 and 1976). Cycle IV extended over five calving seasons (1986 through 1990). Angus and Hereford cows were bred with semen from Hereford and Angus reference bulls (born from 1963 to 1970) and 1980s' bulls (born from 1982 to 1984) as well as Longhorn, Piedmontese, Charolais, Salers, Galloway, Nellore, and Shorthorn bulls. Additionally, some Hereford, Angus, Charolais, Gelbvieh, and Pinzgauer bulls (born from 1983 through 1985) were also used by natural service following an AI period of about $45 \mathrm{~d}$.

All females were retained for evaluation of reproduction, mature weight, height, and other cow traits as well as maternal performance. Length of breeding season was approximately $75 \mathrm{~d}$. Pregnancy was diagnosed by palpation 60 to $75 \mathrm{~d}$ after the end of the breeding season. All heifers diagnosed as not pregnant and cows failing to conceive in two successive years were culled from the breeding herd. Animals were not culled for any growth criteria. Yearling heifers were weighed at the beginning and end of the mating season and when palpated for pregnancy. Thereafter, cows were weighed, measured for hip height, and scored for body condition four times each year. One measurement was taken each season: 1) mid-May (spring) at start of the breeding season, 2) beginning of August (summer) at the end of the breeding 


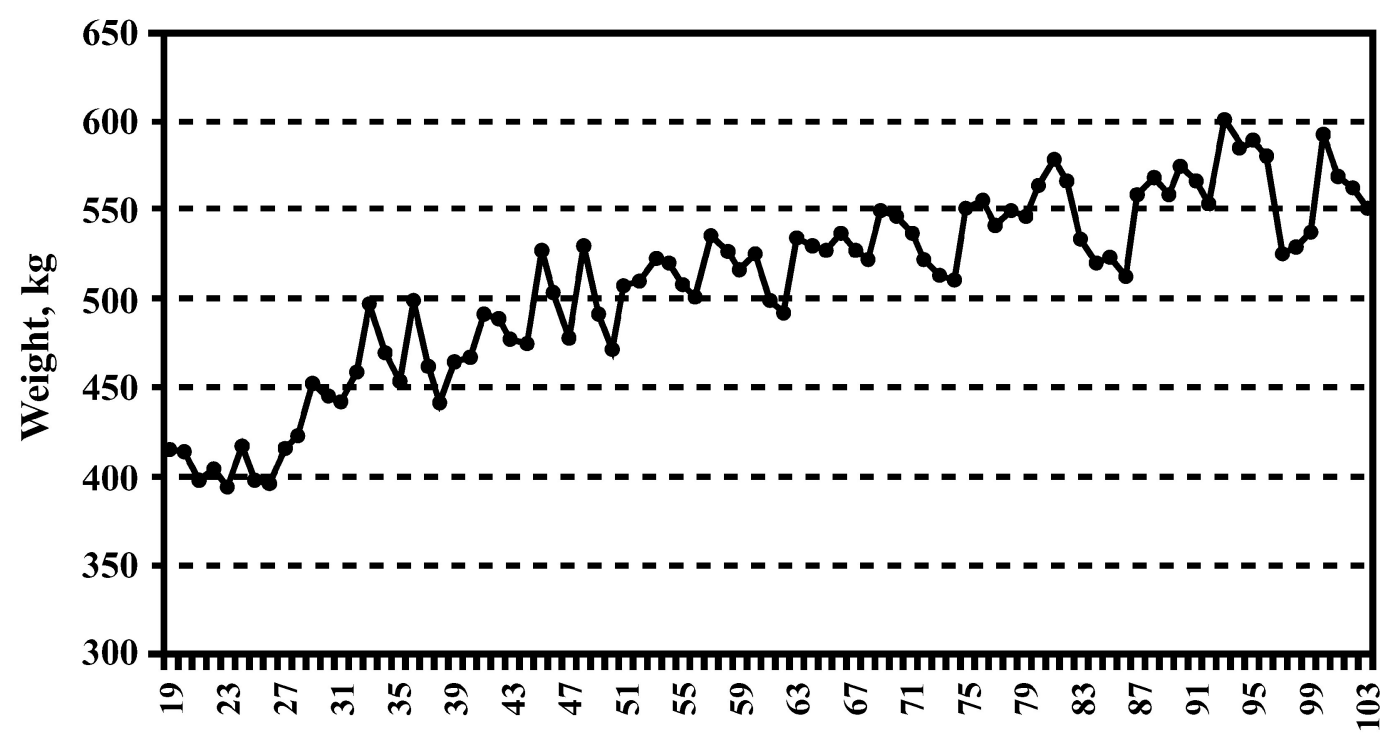

Age, mo

Figure 1. Mean weight by age of Cycle I to IV cows.

season, 3) end of October (fall) at palpation for pregnancy following weaning, and 4) beginning of February (winter) before calving. Each record of a cow was assigned to one of four physiological codes composed of a combination of lactation code ( 1 = not lactating, 2 = lactating) and pregnancy code $(1=$ not pregnant, $2=$ pregnant $)$. The present study included only records of 2-yr-old or older cows with assigned physiological code. Additional details about data edits and management were presented by Arango (2000). Postweaning management and sampling of sires were discussed by Laster et al. $(1976,1979)$ and Gregory et al. (1979) for Cycles I to III, and by Cundiff et al. (1998) and Thallman et al. (1999) for Cycle IV.

A total of 85 ages, ranging from 19 to 103 mo, was represented (Cycles I to IV). The total of 61,798 individual weights was from 3,032 individual cows having between 6 and 28 measurements (up to 4 per year). Most cows $(80 \%)$ had 18 or more recorded measurements. Presented in Figure 1 are unadjusted weights by age (mo), which tended to increase with age and which have a somewhat seasonal fluctuation pattern.

\section{Statistical Methods}

Covariance functions have been proposed as an alternative to deal with trajectory or longitudinal data, such as growth (Kirkpatrick and Heckman, 1989; Kirkpatrick et al., 1990, 1994; Meyer and Hill, 1997). The CF is defined to quantify variation of the growth trajectories about the mean, which is equivalent to the covariance matrix in the finite-dimensional model (Kirkpatrick and Heckman, 1989; Kirkpatrick et al., 1990). The CF can be used to describe the covariance between any two records measured at given ages as a function of the ages and some basic coefficients, which can be determined with traditional linear mixed models. An equivalent proce- dure was proposed originally using random regression models (Henderson, Jr., 1982; Laird and Ware, 1982; Jennrich and Schluchter, 1986). Schaeffer and Dekkers (1994) and Jamrozik and Schaeffer (1997) described the procedure for test-day records of dairy cattle as a method similar to that used with the maternal genetic effects model, with the difference that with RRM the design matrix contains coefficients different from 0 or 1 . The $\mathrm{CF}$ is equivalent to the covariance matrix estimated with RRM using functions of age as covariables. The equivalence between CF and RRM has been described (Meyer and Hill, 1997; Meyer, 1998a; van der Werf et al., 1998; Schaeffer, 1998; Gengler et al., 1999). Orthogonal polynomials often have been the basis of statistical growth curve models (Sandland and McGilchrist, 1979), they represent the coefficients most widely used to describe size-age relationships in animals (Fitzhugh, 1976), and they have been chosen as suitable functions to represent coefficients for the CF (Kirkpatrick et al., 1990, 1994; Meyer and Hill, 1997) and for RRM (Meyer, 1998a,c; 1999, 2000; van der Werf et al., 1998). The most important property of orthogonal polynomials is "intrinsic and numerical simplicity," which allows numerical computation to an accuracy limited only by round-off error (Thompson, 1997). In general, polynomial regression provides flexibility for modeling continuous response functions by adding terms until the data are fitted with the desired lack of distortion. Matrices of orthogonal polynomials have columns that are mutually orthogonal, which avoid the problem of near-singularity that is common with the "natural" polynomials. Meyer (2000) concluded that orthogonal polynomials can be recommended as general-purpose functions for modeling growth data, especially if higher orders of fit are needed. However, orthogonal polynomials suffer some deficiencies when used to model growth data: 1) they do not model cyclic 
patterns, which are typical for growth subject to seasonal effects, and 2) they are not asymptotic, which is a problem in modeling growth trajectories that reach a plateau at maturity. Orthogonal polynomial coefficients, based on the set of ages (times) represented in the data, should be standardized to the range $-1 \leq a \leq 1$ (Kirkpatrick and Heckman, 1989). The set of orthogonal polynomials of age can be arranged in a matrix $(\boldsymbol{\Phi}=\mathbf{M} \mathbf{\Lambda})$, which is the product of a square matrix containing the coefficients of the Legendre polynomials $(\boldsymbol{\Lambda})$ of a given order $(n \times n)$ and another matrix $(\mathbf{M})$ containing the polynomials of the corresponding standardized ages $\left(a_{i}^{* 0}, a_{i}^{* 1}, a_{i}^{* 2}, \ldots\right.$,

$$
\begin{aligned}
y_{i j} & =F+\sum_{m=0}^{\mathrm{n}-1} b_{m} \phi_{m}\left(t_{i j}\right)+\sum_{m=0}^{n_{G}-1} \alpha_{i m} \phi_{m}\left(t_{i j}\right)+\sum_{m=0}^{n_{P}-1} \gamma_{i m} \phi_{m}\left(t_{i j}\right)+\varepsilon_{i j} \\
\boldsymbol{y} & =\boldsymbol{X} \boldsymbol{b}+\boldsymbol{Z} \boldsymbol{a}+\boldsymbol{Z}^{*} \boldsymbol{p}+\boldsymbol{e}
\end{aligned}
$$

where $F$ are the fixed effects in the model; $\phi_{m}\left(t_{i j}\right)$ are the covariates as a function of age with $t_{i j}$, the $\mathrm{j}^{\text {th }}$ age of animal $i$ standardized to the range -1 to 1 , and with $\phi_{m}$, the $\mathrm{m}^{\text {th }}$ orthogonal Legendre polynomial for $n$ the order of fit (with $\phi_{m}$ evaluated for $\mathrm{t}_{i j}$, there will be $\mathrm{n}$ coefficients for each age); $b_{\mathrm{m}}$ is the $\mathrm{m}_{\text {th }}$ fixed regression coefficient; $\alpha_{i m}$ and $\gamma_{i m}$ are the $\mathrm{m}^{\text {th }}$ additive genetic and permanent environmental random regression coefficients for cow $i$; $n_{\mathrm{G}}$ and $n_{\mathrm{P}}$ are orders of fit for the additive genetic and permanent environmental effects; and $\varepsilon_{i j}$ is the temporary environmental effect or measurement error. The RRM is an extension of the regular linear mixed model, but with incidence matrices $(\mathbf{X}$ and $\mathbf{Z})$ containing coefficients other than zeros and ones. Coefficients of 1 are replaced by functions of ages at which the records are taken (i.e., $\left.\phi_{m}\left(t_{i j}\right)\right)$. The "design" matrix of covariates (standardized ages, incorporating orthogonal polynomial coefficients) is $\boldsymbol{Z}$ for all animals and $\boldsymbol{Z}^{*}$ is the part of $\boldsymbol{Z}$ corresponding to cows with records (i.e., nonzero part). The model's first and second moments are

$$
\begin{gathered}
\boldsymbol{E}[\boldsymbol{y}]=\boldsymbol{X} \boldsymbol{b} \text { and } \\
V(\boldsymbol{y})=\boldsymbol{Z}\left(\boldsymbol{K}_{\boldsymbol{G}} \otimes \boldsymbol{A}\right) \boldsymbol{Z}^{\prime}+Z^{*}\left(\boldsymbol{K}_{\boldsymbol{p}} \otimes \boldsymbol{I}\right) \boldsymbol{Z}^{*}+\boldsymbol{R}
\end{gathered}
$$

where $\mathbf{A}$ and $\mathbf{I}$ are the numerator relationship matrix and an identity matrix, respectively; $\boldsymbol{K}_{\boldsymbol{G}}$ and $\boldsymbol{K}_{\boldsymbol{P}}$ are the matrices of genetic and permanent environmental (co)variances (coefficients of the $\mathrm{CF}$ ), with dimensions equal to the order of the covariance matrices in the analysis; and $\boldsymbol{R}$ is the variance of the temporary environmental effects, which is a diagonal matrix allowing for different variances by age $t$.

Applications of CF-RRM to growth and related traits have included papers by Andersen and Pedersen (1996) in pigs. Koenen and Veerkamp (1998) used it for live weight, condition score, and feed intake; Koenen et al. (1999), for live weight and live weight changes; Jones et al. (1999), for condition score; and Veerkamp and Thompson (1999), for live weight and feed intake of dairy cows. $\left.a_{i}^{* \mathrm{n}-1}\right)$, with rows $\boldsymbol{\Phi}_{\mathrm{n}}=\mathbf{a}^{*}{ }_{\mathrm{i}} \Lambda$. The elements of the covariance matrix (e.g., G, the additive genetic covariance matrix) can be expressed in terms of matrices that are defined by the Legendre polynomial functions and by the standardized age values as $\mathbf{G}=\boldsymbol{\Phi} \mathbf{K} \boldsymbol{\Phi}^{\prime}=\mathbf{M}\left(\boldsymbol{\Lambda} \mathbf{K} \boldsymbol{\Lambda}^{\prime}\right) \mathbf{M}^{\prime}=$ $\mathbf{M} \Omega \mathbf{M}^{\prime}$ (1), where $\mathbf{K}$ is a matrix of coefficients, which determines the $\mathrm{CF}$ as a function of the "coefficient matrix" $\left(\Omega=\Lambda \mathbf{K} \Lambda^{\prime}\right)$ and the ages adjusted to the range for which the polynomial is defined (M). Following the notation of Kirkpatrick et al. (1990, 1994), the RRM model for records over time (including additive genetic and permanent environmental random effects) would be as follows:

For growth of beef cattle, the method was outlined by Varona et al. (1997) and used by Meyer (1998a, 1999, 2000) for cows, and by Meyer (2001) and Albuquerque and Meyer (2001) for young animals.

\section{Statistical Analysis}

Preliminary analyses were done to determine fixed effects affecting weight using Proc Mixed in SAS (Littell et al., 1996) and to find the best order of fit for fixed regression on age to model population trajectory. The quadratic regression on age was the highest order polynomial that was significant. Therefore, quadratic regression was used in the fixed part of the models for all CFRRM analyses, which allowed use of the likelihood ratio test to determine the optimum order of fit (and rank) of the random regression coefficients (Meyer, 1998a, 1999). The set of fixed effects used in the CF-RRM analyses for cow weight included the same effects as for previous finite-dimensional analyses (Arango et al., 2002): sire line, dam line, age (yr), and season and their interactions; year of birth; pregnancy-lactation code; plus quadratic fixed regression on orthogonal polynomials of age. That model was used to allow comparison of estimates of variance components with CF-RRM and finite-dimensional approaches.

The matrices, $\boldsymbol{K}_{\boldsymbol{G}}$ and $\boldsymbol{K}_{\boldsymbol{P}}$, corresponding to the additive genetic and permanent environmental covariance functions $(\boldsymbol{G}$ and $\boldsymbol{P})$, were estimated as covariance matrices for the corresponding random regression coefficients. Additive genetic and permanent environmental random effects for the CF-RRM analyses were assumed to be uncorrelated, as with usual linear animal model analyses. The CF-RRM analyses were carried out by REML using the DFREML-DxMRR programs (Meyer, 1998b,d). The software allows choice of two algorithms to maximize the likelihood function $(\ell)$ : derivative-free (DFREML: with the Simplex or Powell algorithms) and average information (AI-REML). The CF-RRM analyses were done with age of the cow expressed in months. For 
an order of fit, $\mathrm{n}$, the exponents of age range from 0 (i.e., the first term of the polynomial is a scalar) to $n-1$. Therefore, $\mathrm{n}=2$ is linear regression and so on. Initially, additive genetic and permanent environmental covariance functions were obtained for the same order of fit $\left(\mathrm{n}_{\mathrm{G}}=\mathrm{n}_{\mathrm{P}}\right)$. Later, each was allowed to have a different order of fit. Orders of fit considered were 1 to 5 , but only selected combinations were analyzed. Greater orders of fit were not explored due to the computing time that would have been required. Analyses forcing the covariance matrices $\left(\mathbf{K}_{\mathrm{G}}\right.$ and $\mathbf{K}_{\mathrm{P}}$ ) to have reduced rank, as described by Meyer (1998a), were also carried out for selected analyses of different orders of fit, to find a parsimonious model. Alternative models were compared using the likelihood ratio test.

Temporary environmental effects (measurement errors) were assumed to be independently distributed. Two sets of analyses were done considering temporary environmental effects: to have constant variance over all ages or to have different variances for each age (in years) represented in the data (heterogeneous variances). Preliminary analyses determined that models using heterogeneous error variances were significantly superior to models with a single residual variance. Analyses with a different error variance for each age in months represented in the data were extremely slow to converge. Even though the log likelihood improved significantly, the improvement did not offset the extra computing load and time required for the computing resources available. Thus, only heterogeneity of residual variances by years of age was modeled (i.e., residual variances representing ages 2 to 8 ). Reconstructed covariance matrices were obtained among all ages (in months) represented in the data from estimates of elements of the corresponding $\mathrm{CF}$ matrix. Local convergence was initially declared when the variance of the $\ell$ was less than $10^{-7}$; however, that criterion was relaxed (i.e., no changes to the second decimal point for $\ell$ or for parameter estimates) in analyses with a large number of parameters, which had remarkably slow convergence. Arango (2000) presented details about the statistical methods and analyses.

\section{Results and Discussion}

\section{Log Likelihoods}

With 85 ages represented, almost any model is computationally more feasible than the full (unstructured) multivariate model because of the great complexity and computational demand of a model including measurements at all ages as different traits. Several analyses with different orders of fit and ranks were tried to find a parsimonious model that described the data adequately with a moderate number of parameters. The $\ell$ values improved significantly each time the additive genetic and the permanent environmental random regression parts of the model were modeled with increased orders of fit, as shown in Table 2 for models 3-1-1 to 3-4-4 (i.e., fixed regression of order 3 and $n_{G}=n_{P}=\mathrm{n}=1,2,3$, and 4),

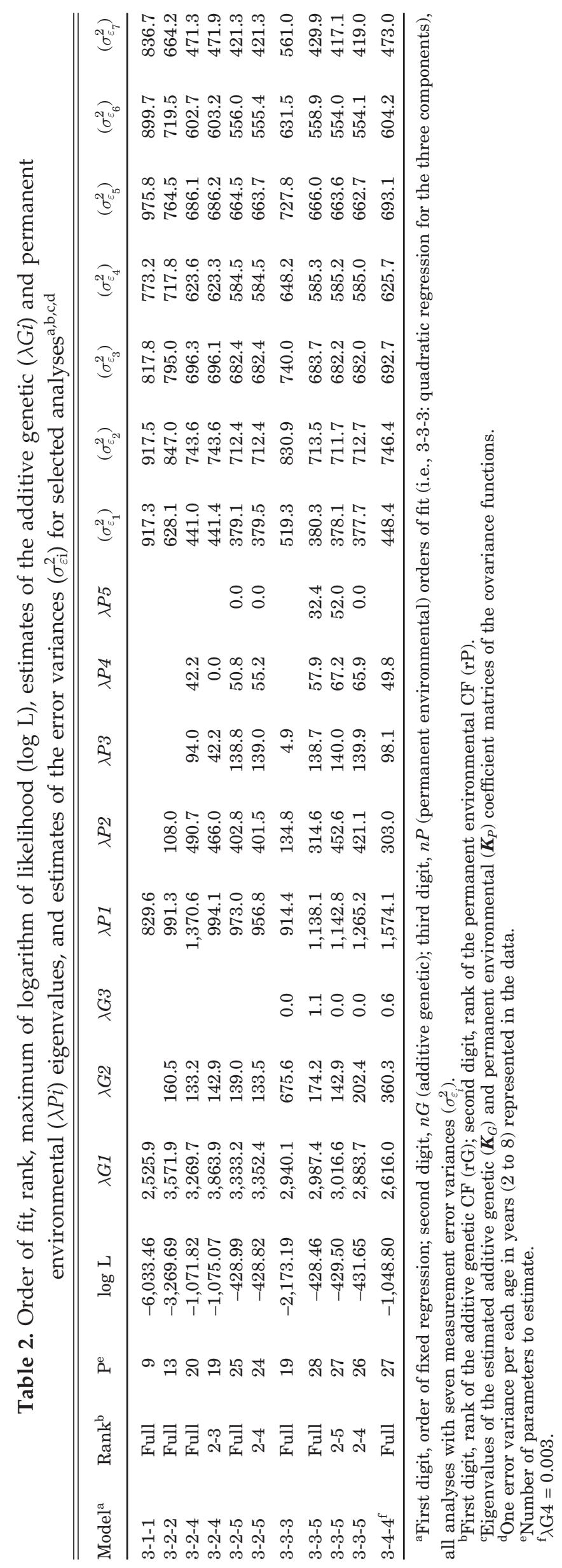


with $9,13,19$, and 27 parameters to estimate (consisting of seven residual variances plus the elements of coefficient matrices $\mathbf{K}_{\mathrm{G}}$ and $\mathbf{K}_{\mathrm{P}}$ ), respectively. Analyses were started with guessed values for the (co)variances between additive genetic and permanent environmental random regression coefficients. Values for the first order were assumed from estimates with finite dimensional models (Arango et al., 2002). Initial values for higher order polynomials were taken from literature reports (Meyer, 1998a, 1999, 2000). In general, convergence was remarkably slow. For most analyses, several restarts were required before $\ell$ stabilized and a global maximum was reached (when $\ell$ did not change at the second decimal on consecutive restarts), especially for analyses when one or more eigenvalues of the $\mathbf{K}_{\mathrm{G}}$ and $\mathbf{K}_{\mathrm{P}}$ were close to zero. In some cases, the likelihoods stabilized to a false local maximum, which was evident if the likelihood improved when the maximization procedure was changed (i.e., from AI-REML to DF-REML). Meyer (1999) reported the same problem, which was due to failure of the search procedure with a high number of parameters and estimates near the boundary of the parameter space (eigenvalues close to zero), even with more than one "restart" of the maximization procedure. Some analyses stopped with an iterative run in progress and provided numerical exception error messages or failed to improve the log likelihood, which might be a sign of numerical or mathematical instability. These failures occurred when a number of unnecessary parameters were included. Convergence problems have been indicated as the cause of discrepancies between genetic variances obtained from CF-RRM and multitrait models for live weight during the first $25 \mathrm{wk}$ of lactation of Holstein heifers (Koenen and Veerkamp, 1998) and also for analyses of live weight during the first 15 wk of lactation of Holstein heifers (Veerkamp and Thompson, 1999) using a different program (ASREML, Gilmour et al., 1999), for which analyses with order $\mathrm{k}=4$ and $\mathrm{k}=2$ did not converge for univariate and multivariate (milk yield and feed intake) models, respectively.

\section{A Parsimonious Model}

The search for a parsimonious model that would fit the data adequately with the least complexity was attempted by concentrating on models that included different orders of fit for the additive genetic and the permanent environmental random regression parts and that used a different temporary environmental variance for each year of age represented (i.e., seven error variances). Previous analyses with growth data in beef cattle have fitted additive genetic and permanent environmental (co)variances with the same order of polynomial regression (Meyer and Hill, 1997; Meyer, 1998a, 1999). Veerkamp and Thompson (1999) used equal and different orders of fit for the RRM of live weight of dairy heifers during the first $15 \mathrm{wk}$ of lactation using the ASREML program (Gilmour et al., 1999).
Table 2 shows the number of parameters, likelihood values, eigenvalues of the estimated coefficient matrices, and estimates of the error variances for selected analyses. The results indicate that the simple repeatability model (the intercept model; 3-1-1) was not statistically adequate. The likelihood values were significantly smaller for the intercept model than for any other model. The greater estimates of error variances at each age with the repeatability model indicate that those variances tended to pick up variation due to insufficient order of fit (Meyer, 1999).

For all other analyses, order of fit of rank 2 sufficed to model the polynomial regression for additive genetic effects. The third eigenvalue $\left(\lambda G_{3}\right)$ was nearly 0 for analyses with orders greater than 2 and models with order 3 but with rank of 2 had likelihood values similar to the corresponding full model, regardless of the rank for the permanent environmental effects (models 3-3-5 with ranks 3-5, 2-5, and 2-4, respectively). In some cases, likelihoods at convergence did not agree with the theoretical expectation that a more complex model would have a better $\ell$. For example, likelihood values for models with $\mathrm{n}_{\mathrm{G}}=3$ and $\mathrm{n}_{\mathrm{P}}=5$ (3-3-5, reduced rank models) were slightly smaller than likelihood values for submodels with $\mathrm{n}_{\mathrm{G}}=2$ and $\mathrm{n}_{\mathrm{P}}=5(3-2-5$, ranks full and 2-4). If the additional parameters do not improve modeling of additive genetic effects, the likelihood should not change and estimates of the additional parameters should be 0 . The reason for that unexpected arithmetic result, which occurred when different orders of fit were chosen for the genetic and the permanent environmental effects, is not clear. The discrepancy may be due to some problem with the implementation of the algorithms. Differences of small magnitude, however, such as the ones reported here, might indicate numerical problems in locating the maximum for the log likelihood (K. Meyer, personal communication). Similar convergence problems were reported by Meyer (1999) using DxMRR, even with more than one restart of the optimization procedure, and they were also evident in Albuquerque and Meyer (2001). In fact, analyses with model 3-3-5 required several restarts and stopped a few times with an iterative run in progress. A higher order polynomial seemed to be required to model the permanent environmental random (co)variance structure than was required to model the genetic covariance. Orders of fit of 4 and 5 provided the best likelihood values.

The parsimonious model was found to have orders of fit 2 and 5 for the additive genetic and permanent environmental effects, respectively, but with a reduced rank of 4 for the permanent environmental part (model 3-2-5, rank 2-4). That model had the largest likelihood value (among the tested models) of -428.82 but was not significantly different from that for the full model (3-25 ) of -428.99 . The model had 24 parameters ( 1 less than the full model). A subset of four linear combinations of the five polynomials sufficed to fit the trajectory. That result is different from fitting linear and cubic regressions for the additive and the permanent environmental 
effects (model 3-2-4), which resulted in a model requiring 20 parameters but which was significantly inferior to the proposed "parsimonious" model. The parsimonious model was also better than the model with quadratic and quartic polynomial regression for the additive genetic and the permanent environmental effects, with reduced ranks of 2 and 4 (model 3-3-5, rank 2-4). Likelihoods were not significantly different, but the parsimonious model required two parameters less than the 3-3-5, rank 2-4 model. That result was confirmed with several restarts of the iteration, and it might indicate a failure of the maximization procedure to locate the maximum of the likelihood for the latter model, which contained unnecessary components of the additive genetic $\boldsymbol{K}_{\mathbf{G}}$.

Meyer and Hill (1997) compared the CF-RRM model and an unstructured five-trait multivariate animal model using annual weights of Australian beef cows between 2 and $6 \mathrm{yr}$ of age. They used the same order of fit for the genetic and permanent environmental $\mathrm{CF}$ and concluded that the repeatability model did not statistically describe the data adequately. They found that the likelihood did not increase significantly for $\mathrm{n}>2$, which indicated that the growth trajectory could be described by a linear trend in the (co)variance structure, which agrees with the present study for the additive genetic effects. Meyer (1998a) reanalyzed data from Meyer and Hill (1997) with ages at weighing in months (19 to 70) with a RRM with increasing order of fit (up to six) but with restriction of the ranks of the genetic and permanent environmental components to one and to three. She found that the likelihood improved until order of $n=4$. She indicated that change in scale was expected to have little effect on the estimates and suggested that the stronger pattern for covariances observed in the second study (Meyer, 1998a) was due to less variation being removed by fixed effects. Meyer (1999) used a RRM to analyze monthly weights of 2- to 10-yr-old (19 to 119 mo) Australian Hereford and Wokalup cows. The environment was characterized by strong seasonal effects. Records taken in January were chosen for analysis. That study compared various sets of fixed effects and definitions of contemporary groups, orders of fit and rank, and transformations of the data to find the most suitable model. She concluded that orders of fit of $n=3$ and $n=$ 4 were appropriate for Herefords and Wokalups, respectively. Examination of full and reduced rank models indicated that rank of $\mathrm{m}=2$ sufficed to model permanent environmental variation, but ranks of $m=3$ for Herefords and of $m=2$ for Wokalups were needed for genetic variation. The final model also transformed ages to log scale and included seven residual variances, resulting in 23 and 21 parameters to be estimated for Herefords and Wokalups, respectively (Meyer, 1999). The results for Wokalups agreed with those in the present study for the genetic CF. For live weight during the first $25 \mathrm{wk}$ of lactation of Holstein heifers, Koenen and Veerkamp (1998) also found that $\mathrm{CF}$ with order of fit of $\mathrm{n}=2$ sufficed to model additive genetic variation, as for cow weight in the present study. Veerkamp and Thompson (1999) reported that the likelihood improved until order $n=4$, although the higher order was primarily needed to model permanent environmental effects. In their study, an order of $n=3$ was sufficient to model additive genetic effects for live weight during the first 15 wk of lactation of Holstein heifers.

\section{Covariance Functions}

The estimated $\mathrm{CF}$ for additive genetic $(G)$ and permanent environmental $(P)$ effects for the parsimonious model are

$$
\begin{aligned}
& G\left(a_{i}^{*}, a_{i}^{*}\right)=\left[1 a^{*}{ }_{j}\right]\left[\begin{array}{ll}
1593.35 & 615.90 \\
615.90 & 448.78
\end{array}\right]\left[\begin{array}{l}
1 \\
a^{*}{ }_{j}
\end{array}\right] \text { and }
\end{aligned}
$$

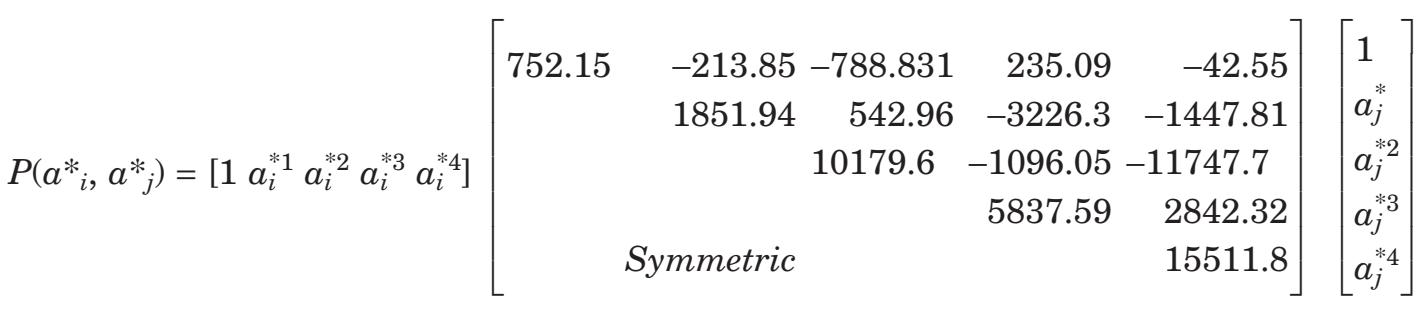

with $a^{*}{ }_{i}$ and $a^{*}{ }_{j}$ denoting the $\mathrm{i}^{\text {th }}$ and $\mathrm{j}^{\text {th }}$ ages in the standardized range $\left(-1<a^{*}<1\right)$.

The first eigenvalue of the coefficient matrix of the additive genetic $\mathrm{CF}$ explained about $96 \%$ of the total genetic variance. The corresponding eigenfunction is presented in Figure 2. A positive linear pattern, with moderate slope, was evident for the leading eigenfunction $(0.41$ to 0.97$)$ as the cows aged. The pattern indicates positive genetic correlations across ages as ani- mals reach maturity. In other words, selection for increased weight at any age would tend to increase weight throughout the entire growth period. Another important consequence is that weight measurements early in life can be used to select for mature weight to reduce the generation interval in selection programs. This result agrees with results for multivariate analyses with the "traditional" linear animal model (Arango et al., 2002), which resulted in large genetic correlations 


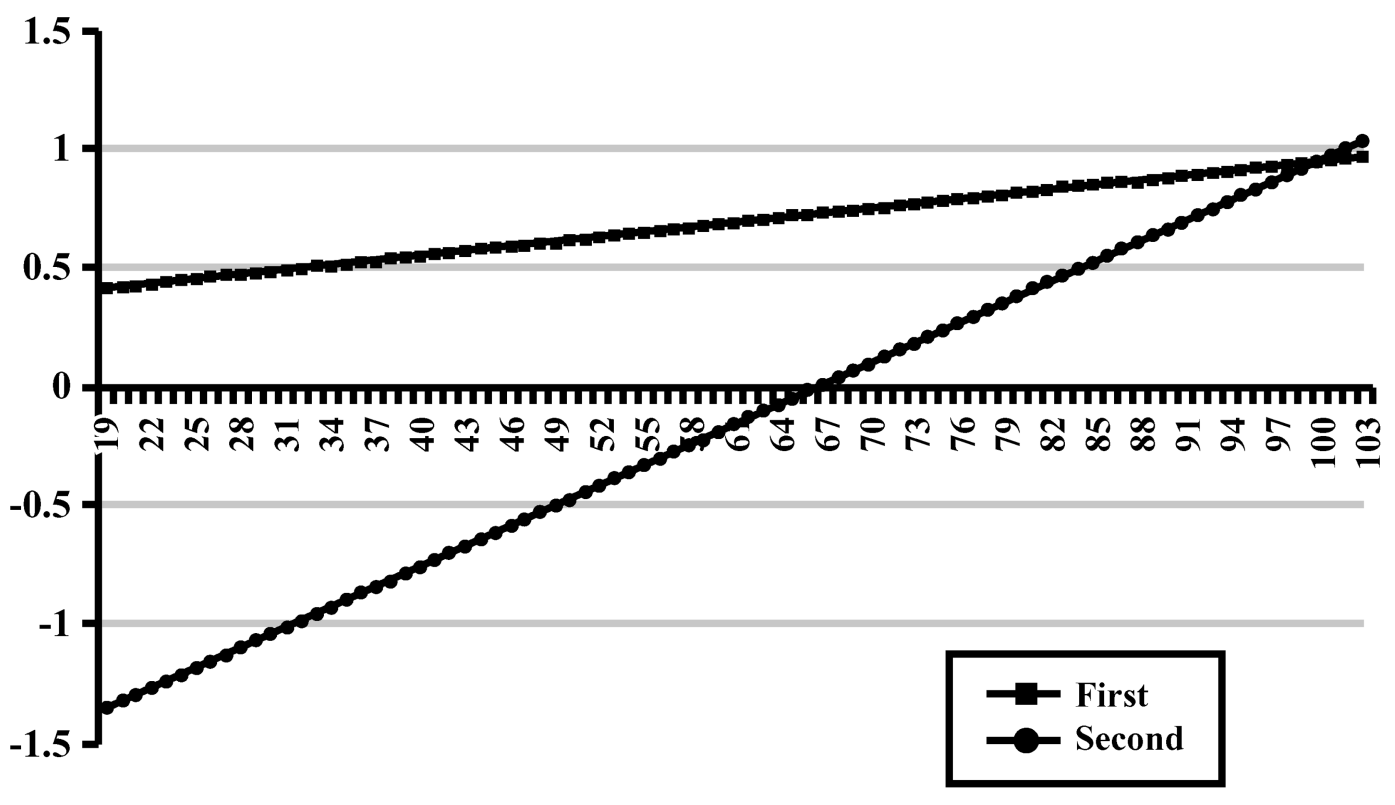

Age, mo

Figure 2. First and second eigenfunctions from estimates of the additive genetic CF coefficient matrix for model 32-5, rank 2-4.

(0.92 to 1.00$)$ between ages. The second eigenvalue accounted only for approximately $4 \%$ of the total variation of additive genetic effects. Meyer and Hill (1997) found that the first two eigenvalues accounted for 97 and $3 \%$ of total genetic variability for orders of fit of $n=2$ and of $\mathrm{n}=5$. Their results agreed with those from a second study that fit ages in months (Meyer, 1998a), in which estimates of eigenvalues for the genetic effects were 0 for orders of fit or rank greater than 2 until $n=4$; for $n \geq 5$, some sizeable genetic eigenvalues were interpreted as possible artifacts of the polynomial function and the univariate fixed effects of the model of analysis (Meyer, 1998a). Meyer (1999), with a wider spread of ages and an additional breed, reported similar results for the spectral decomposition of the CF. With her final model, the first genetic eigenfunction explained most of the variation (92 and 97\% for Hereford and Wokalup, respectively) and followed the same trend, with positive values through all ages. Koenen and Veerkamp (1998) reported that for live weight of Holstein heifers during the first 25 wk of lactation, the first eigenfunction explained $98 \%$ of total genetic variation, showed a liner trend, and was positive throughout the period in agreement with the present study.

\section{Estimates of Variance Components}

Estimates of additive genetic, permanent environmental, and phenotypic standard deviations for the parsimonious model are shown in Figure 3 for the range of ages. In general, estimates of additive genetic standard deviations increased linearly with age from 28 (at 19 mo) to $57 \mathrm{~kg}$ (at $103 \mathrm{mo}$ ). Those estimates agreed well with estimates from univariate and pairwise bivariate analyses of the same data by age (yr) at early and intermediate ages (Arango et al., 2002), although the estimates differed after approximately $6 \mathrm{yr}$ of age. The apparent upward bias of estimates of genetic standard deviations at late ages indicates an inadequacy of CFRRM to model genetic variability at late ages. The difficulty seems to be related to properties of polynomial regression (i.e., growth is asymptotic but polynomial regression is not [S. Kachman, personal communication]), which does not behave well at the extremes of the age range and with the order of fit used to describe the data. The same problem was previously observed using CF-RRM (Meyer and Hill, 1997; Meyer, 1998a, 1999). To alleviate that problem, Meyer (1999) eliminated records of ages 115 to $119 \mathrm{mo}$, transformed ages to $\log$ scale, and used nine instead of six residual variances. The new analyses somewhat decreased the increase in estimates of variances with age but did not cure the problem (estimates were similar). She concluded that "higher order terms in modeling the population trajectory were the source of the problem." Poor estimates of genetic variance at extremes of the trajectory were also observed for lactation curves in dairy cattle (Jamrozik and Schaeffer, 1997; van der Werf et al., 1998).

\section{Genetic (Co)Variances and Correlations}

Estimates of additive genetic covariances (Figure 4) between adjacent ages exhibited an increasing pattern as animals aged, describing an upward tilted plane in a three-dimensional plot. Corresponding genetic corre- 


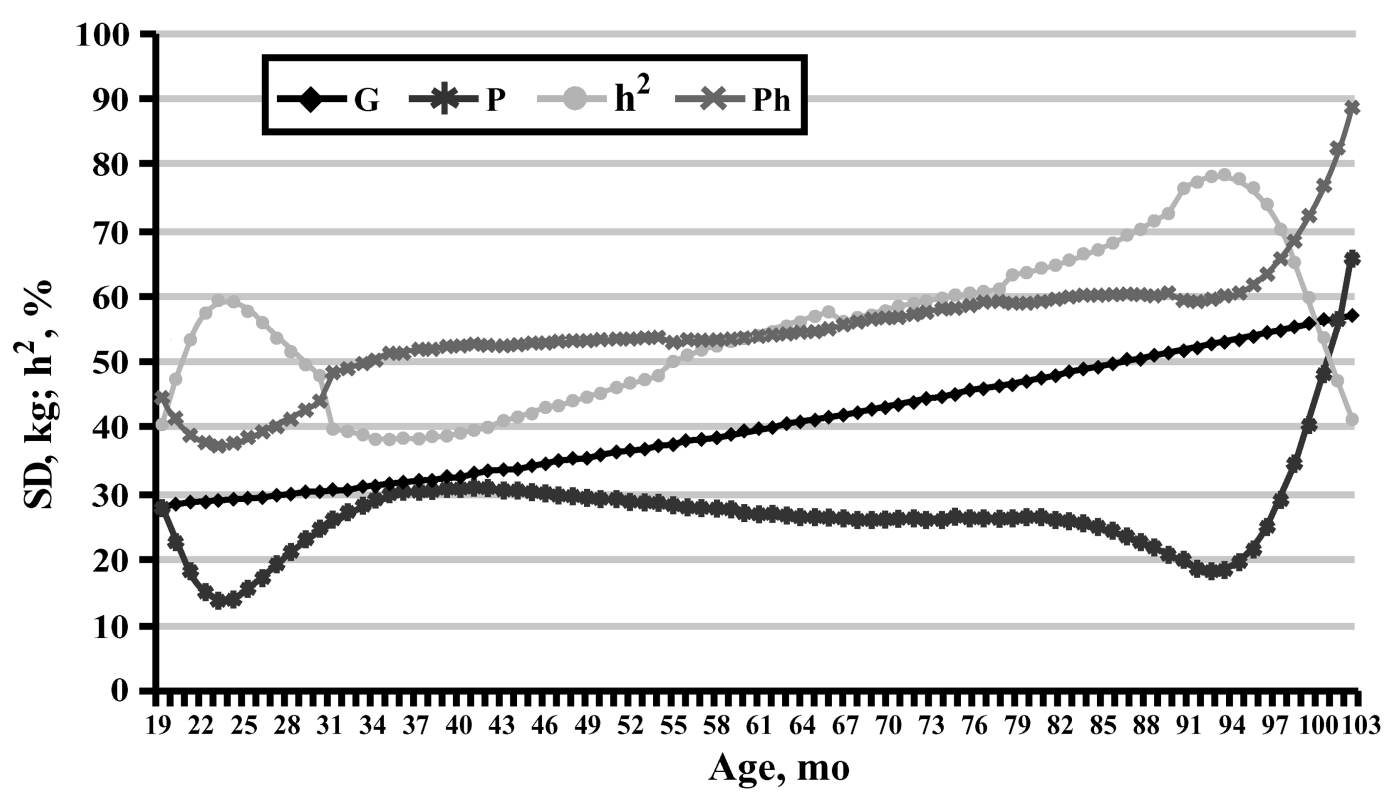

Figure 3. Estimates of additive genetic (G), permanent environmental (PE), and phenotypic (Ph) standard deviations and heritability $\left(\mathrm{h}^{2}\right)$ of monthly weights of Cycle I to IV cows.

lations (Figure 5) exhibited a smooth surface dominated by large values, which formed nearly a plane about unity, except for extreme ages. Genetic correlations declined as the interval between ages increased but were greater than 0.70 for any pair of ages. The measurements at 72 mo of age had estimates of genetic correlations of over 0.84 with all other ages and over 0.90 with ages greater than 28 mo. That pattern agrees with estimates of genetic correlations between measurements at ages of 2 through $6 \mathrm{yr}$ obtained with the finitedimensional model (Arango et al., 2002), which ranged from 0.92 to 1.00 . Those results, along with the dis- agreement for estimates of genetic variance at late ages with the CF-RRM, and the simplicity and robustness of the univariate analysis, seem to indicate that a repeatability model might be an acceptable approximation to model variation for cow weight in this population.

Meyer and Hill (1997) and Meyer (1998a, 1999) found that surfaces of plots of additive genetic covariances and correlations by pairs of ages depended on the order of fit chosen. Their plots represented an upwardly tilted plane, as in the present study, when fitting age with the CF-RRM for yearly weights (Meyer and Hill, 1997).

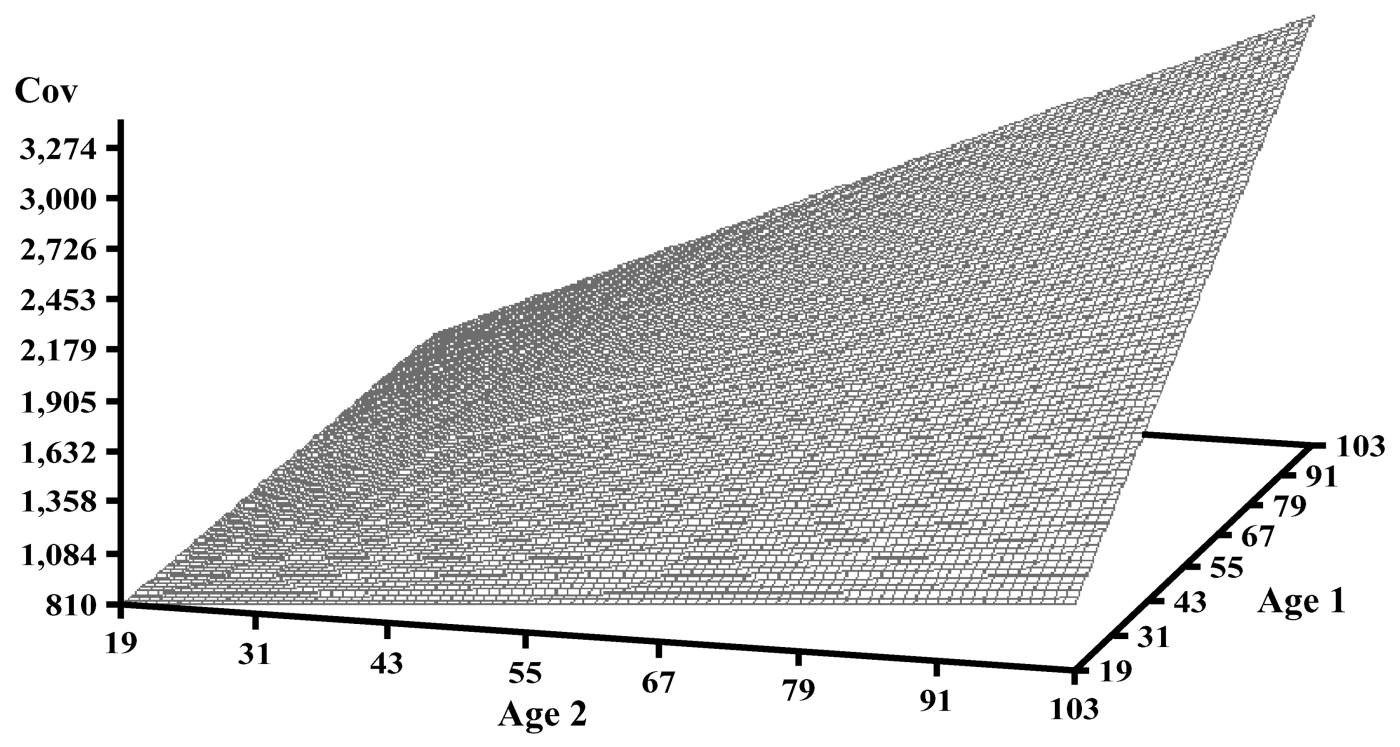

Figure 4. Estimates of genetic (co)variances (Cov) between monthly weights for ages 1 and 2 (Age 1, Age 2) with model 3-2-5, rank 2-4. 


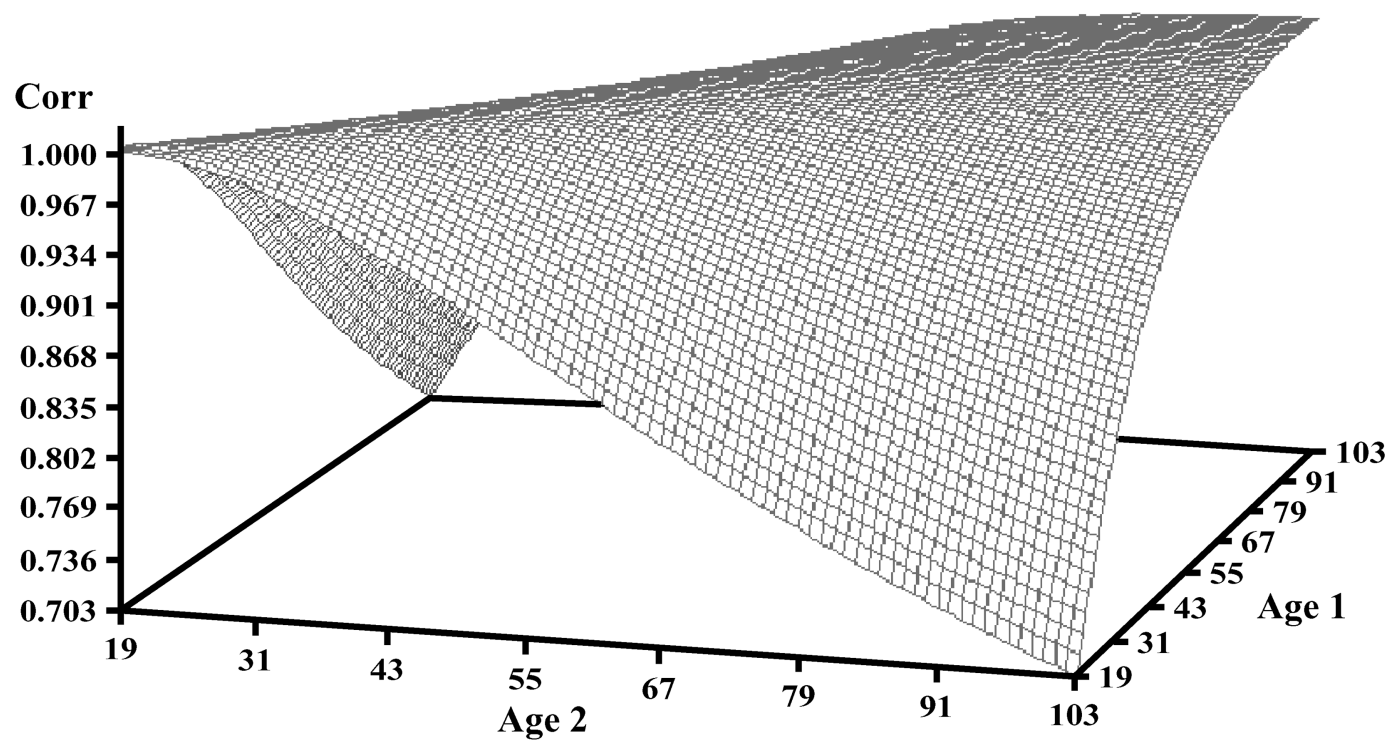

Figure 5. Estimates of genetic correlations (Corr) between monthly weights for ages 1 and 2, (Age 1, Age 2) with model 3-2-5, rank 2-4.

With higher orders of fit ( $\mathrm{n}=3$ and 4 ), the plots of genetic covariances between pairs of ages were smooth and increased until about 5 yr of age and then formed a plateau for Hereford cows (Meyer, 1999). Genetic correlations with $\mathrm{n}=4$ were high across pairs of ages with a plateau close to unity for pairs of ages $3 \mathrm{yr}$ and older for Wokalups (Meyer, 1998a, 1999). For Herefords, the correlations were more variable and as low as 0.23 between extreme ages (19 and 199 mo). For live weight during the first 25 wk of lactation of Holstein heifers, Koenen and Veerkamp (1998) found that a CF of order $\mathrm{n}=2$ defined high genetic correlations between weights for different stages of lactation (0.88 to 1.00 ).

\section{Permanent Environmental and Phenotypic Covariances}

Estimates of permanent environmental and phenotypic standard deviations (Figure 3) increased markedly for measurements at older ages (Figure 3 ). Corresponding covariances and correlations (Figures 6 and 7) among older ages also increased. The apparent weakness of the model for fitting weights at extreme older ages might be due to 1) a lack of mathematical flexibility to model growth adequately with orthogonal polynomials; 2) the small number of records at the extreme age points; and 3) the general property of the regression methods, for which measurements at extreme ages may have important effects on the estimation of regression coefficients. Rawlings et al. (1998) indicated that even with polynomial models of higher order and associated smaller residual sum of squares, the transformation to specific ages might exhibit wild oscillations. Estimates here were within the range of those reported with the finite-dimensional animal model from this study (Arango et al., 2002), except for extreme ages. Meyer (1998a, 1999) reported a similar pattern for covariances of permanent environmental effects with erratic estimates and a large increase in variances for oldest ages. She concluded that "higher order terms in modeling population trajectory were the source of the problem". That might explain a similar pattern for permanent environmental effects $\left(n_{P}=5\right)$ but not for genetic effects $\left(\mathrm{n}_{\mathrm{G}}=2\right)$ in the present study. However, the results would indicate an inadequacy of the model to fit withinyear variation due to seasonal effects. That inadequacy was evident in an analysis of monthly weights subject to strong seasonal effects in Australia (Meyer, 2000). Meyer tried to model the fluctuations in residual error variances with 12 distinct components repeated cyclically and found increases in $\ell$ were somewhat smaller than increases in the $\ell$ from adding 55 parameters to fit individual measurement error variances (318.1 vs. 361.6 for $\mathrm{k}=20$ ). Those results suggested that the model with variances of cyclic errors represents a reasonable compromise between parsimony and adequacy for modeling temporary environmental variation. The results also indicate that some age-specific nonseasonal variation was not explained using the model with cyclic error variances (Meyer, 2000). Meyer (1999) also reported increasing phenotypic variation with age, with variation being greater for Herefords than for Wokalups. Andersen and Pedersen (1996) also reported increased phenotypic variation with time for weight gain with an almost linear trend between 35 to $115 \mathrm{~kg}$ of live weight and also suggested a log transformation to stabilize variation over time.

Analyses with ages transformed to the logarithmic scale and including only ages represented in all cycles (21 to $78 \mathrm{mo}$ ) were also done for the parsimonious model. The analysis on the log scale did not converge after 10 restarts. Estimates in the last round, although somewhat smaller, followed the same pattern as those with 


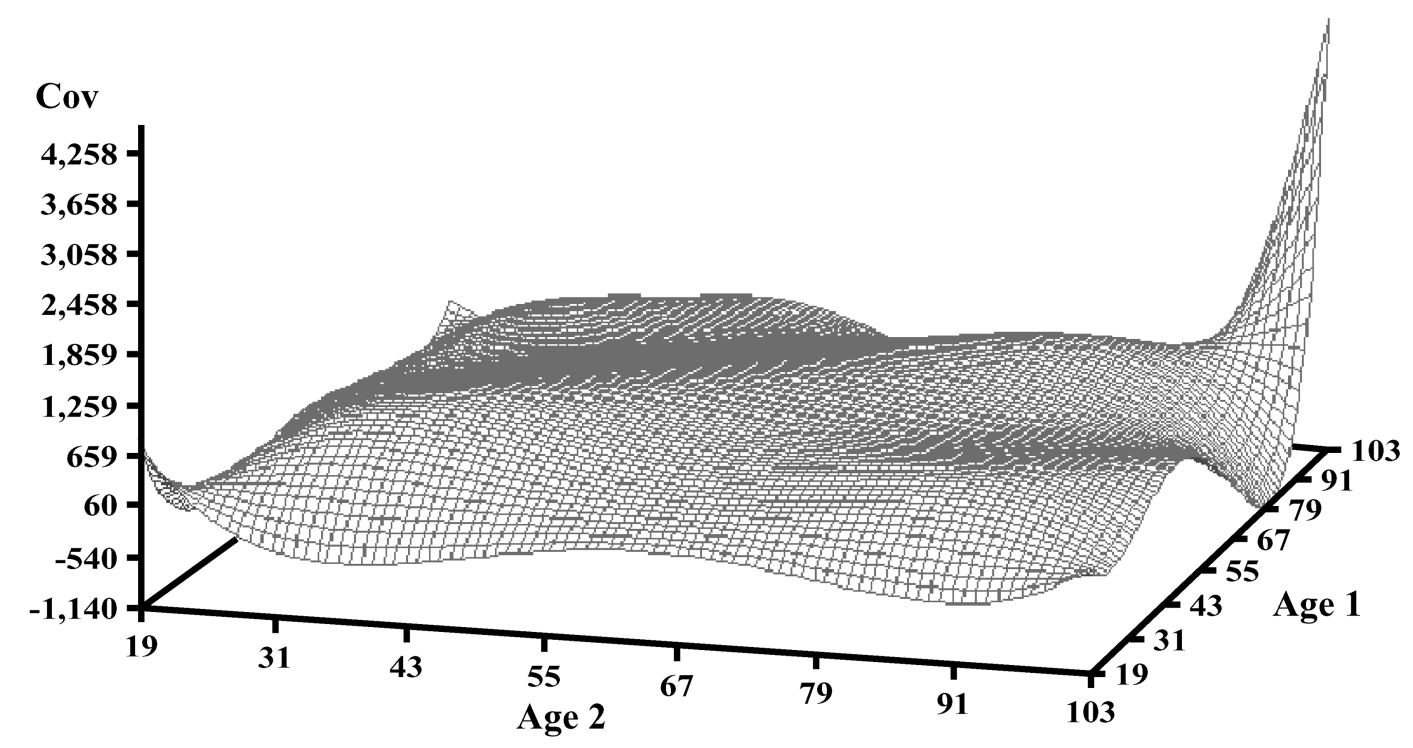

Figure 6. Estimates of permanent environmental (co)variances (Cov) between monthly weights for ages 1 and 2 (Age 1, Age 2) with model 3-2-5, rank 2-4.

the normal scale and, evidently, did not solve the problem of a poor model for extreme ages. The same pattern was found for analyses with fewer ages (21 to $78 \mathrm{mo}$ ), in which estimates of SD were less at extreme ages. The patterns of SD and covariances, however, were the same as for analyses on the normal scale.

Estimates of permanent environmental and phenotypic correlations (Figures 7 and 9) were greater than 0.60 among most pairs of intermediate ages but fluctuated and were smaller among pairs of extreme ages. That pattern was less evident with a lower order of fit (i.e., model 3-3-3). The estimates also might indicate that a higher order polynomial is required to model permanent environmental $\mathrm{CF}$ in these data $\left(\mathrm{n}_{\mathrm{P}}=5\right)$, as suggested by Meyer (1999), who reported small estimates of covariances and correlations between pairs of records at extreme ages for Hereford cows. Estimates of permanent environmental and phenotypic correlations at intermediate ages agreed well with those obtained with the finite-dimensional model (Arango et al., 2002).

Plots of phenotypic covariance and correlation matrices (Figures 8 and 9) showed evident spikes along the diagonals. Those peaks represent inflation of variance probably caused by measurement error variances and other date-specific effects (diseases, seasonal weather

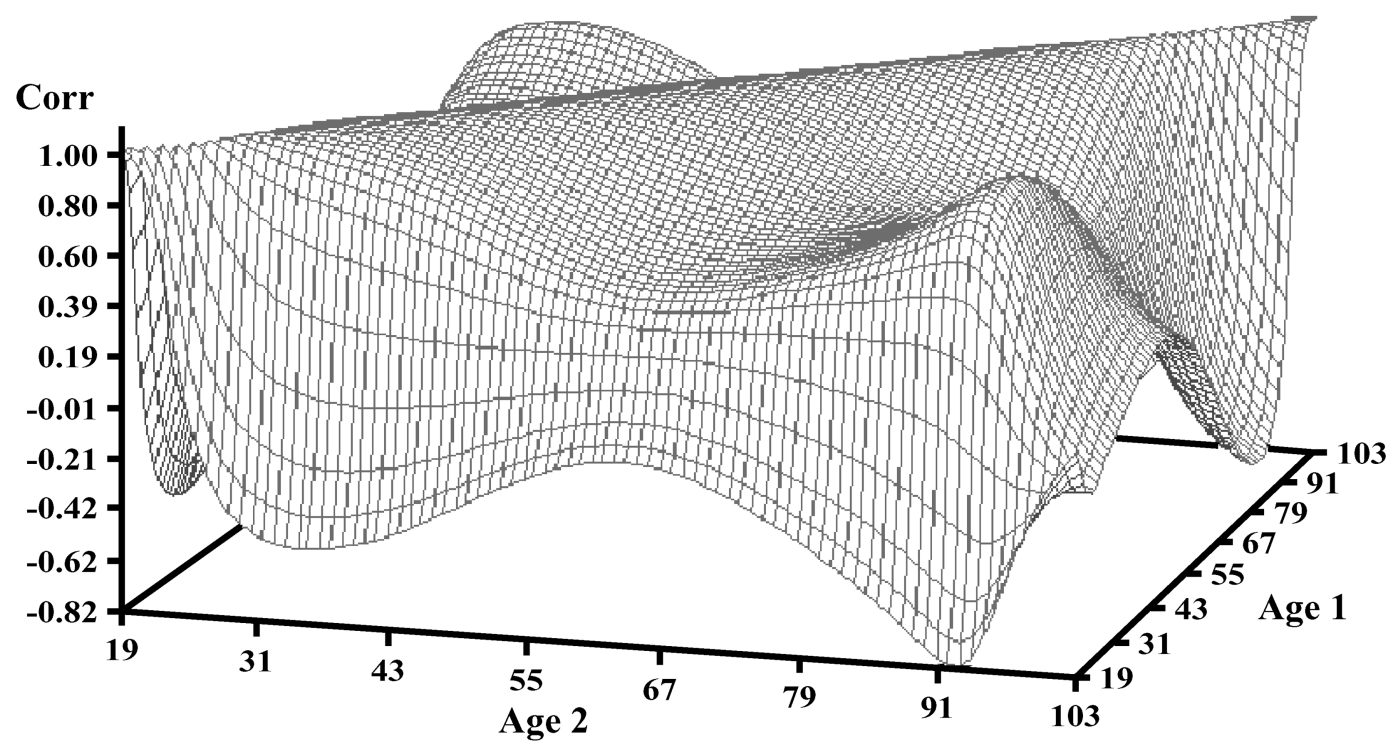

Figure 7. Estimates of permanent environmental correlations (Corr) between monthly weights for ages 1 and 2 (Age 1, Age 2) with model 3-2-5, rank 2-4. 


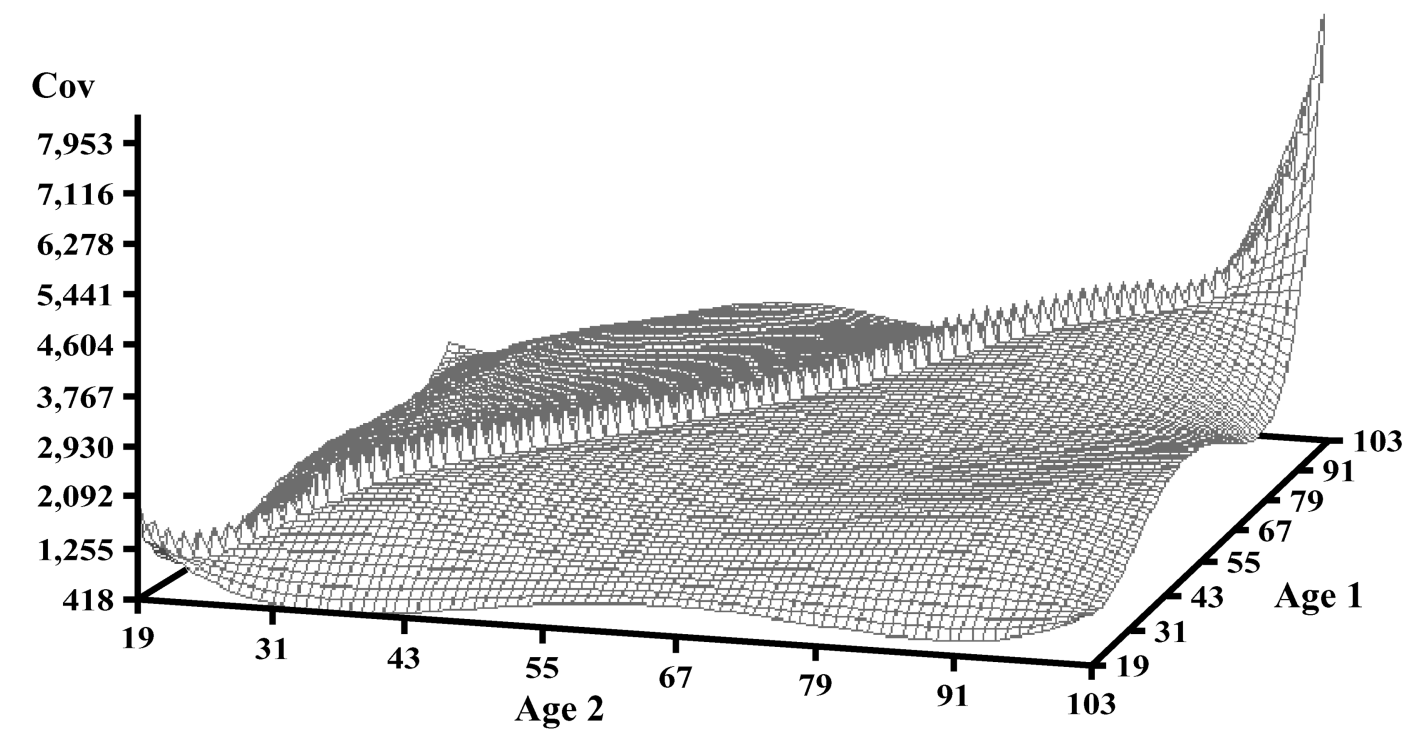

Figure 8. Estimates of phenotypic (co)variances (Cov) between monthly weights at ages 1 and 2 (Age 1, Age 2) with model 3-2-5, rank 2-4.

changes). The increase of the phenotypic variances on the diagonal by the CF-RRM was reported in early applications of infinite-dimensional analyses of lactation curves of Holstein cattle for the estimation of phenotypic covariance structure (Kirkpatrick et al., 1994). Meyer and Hill (1997) and Meyer (1998a, 1999) also reported diagonal peaks of inflation for phenotypic variances, implying temporary environmental variance.

\section{Heritability Estimates}

As with estimates of additive genetic variances, estimates of heritability also tended to increase with age (0.38 at 35 to $37 \mathrm{mo}$, to 0.78 at 92 to $95 \mathrm{mo}$ ). The excep- tions were estimates at extreme ages, which were dominated by fluctuations in estimates of error variances. Heritability estimates were smallest at about $3 \mathrm{yr}$ of age, corresponding to the large error variance at that age (Table 2). The negative but complementary relationship between estimates of permanent environmental variance and estimates of genetic variance was evident over time, as those components of variance tended to balance each other. That pattern was also found with the finite-dimensional analyses (Arango et al., 2002). Estimates of heritability with the CF-RRM were similar to estimates with the repeatability model ( 0.51 to 0.58$)$ and the multivariate finite-dimensional ( 0.50 to 0.66 ) models, except at older ages when estimates using the

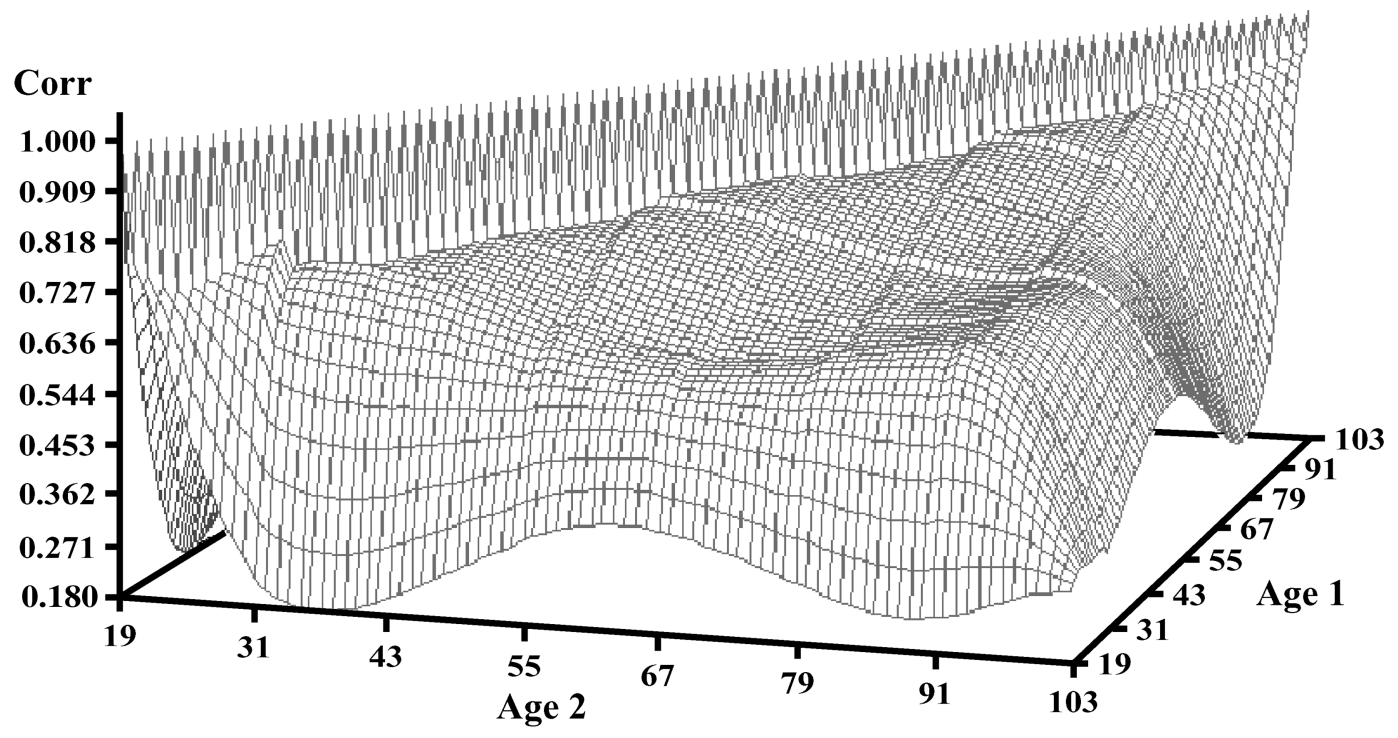

Figure 9. Estimates of phenotypic correlations (Corr) between monthly weights at ages 1 and 2 (Age 1, Age 2) with model 3-2-5, rank 2-4. 
CF-RRM were larger (over 0.70 after $88 \mathrm{mo}$ ). That result further suggests the deficiency of the model to fit data at extremes of the age range and indicates that prediction of breeding values or permanent environmental effects using the CF-RRM should be considered with caution. Nevertheless, for practical selection purposes, such estimates might not be an important constraint because selection using weights at such later ages usually would not be practiced. Meyer (1999) also found estimates of heritability with CF-RRM to be from 0.37 to 0.57 (19 to $119 \mathrm{mo}$ ), which were somewhat larger than the 0.31 obtained with a repeatability model with age (yr) as a fixed effect (Meyer, 1995) for Hereford cows. She reported estimates of heritability that agreed well between the two models for Wokalups, ranging from 0.42 to 0.49 for the $\mathrm{CF}$ model and 0.48 for the repeatability model (Meyer, 1999).

\section{Implications}

This research suggests that covariance structures for permanent environmental effects are complex to model, which forced the use high polynomial orders. On the other hand, most of the genetic effects are highly correlated through the age trajectory and could be acceptably modeled by a linear trend. In fact, genetic correlations were high among all ages for which one may presume that selection for adult weight could be applied. Although the linear repeatability model did not fit the data mathematically as well as more complex random regression models for cow weights, a simple repeatability model similar to those now used for routine national cattle evaluations might be an acceptable approximation for practical purposes to compute expected progeny differences for mature weight given the simplicity and robustness of the repeatability model.

\section{Literature Cited}

Albuquerque, L. G., and K. Meyer. 2001. Estimates of covariance functions for growth from birth to 630 days of age in Nellore cattle. J. Anim. Sci. 79:2776-2789.

Andersen, S., and B. Pedersen. 1996. Growth and food intake curves for group-housed gilts and castrated male pigs. Anim. Sci. 63:457-464.

Arango, J. A. 2000. Genetic study of weight, height and body condition score in beef cows. Ph.D. Diss. Univ. of Nebraska-Lincoln.

Arango, J. A., L. V. Cundiff, and L. D. Van Vleck. 2002. Genetic parameters for weight, weight adjusted for condition score, height and body condition score in beef cows. J. Anim. Sci. 80:3112-3122.

Cundiff, L. V., K. E. Gregory, and R. M. Koch. 1998. Germplasm evaluation in beef cattle-Cycle IV: Birth and weaning traits. J. Anim. Sci. 76:2528-2535.

Fitzhugh, H. A., Jr. 1976. Analysis of growth curves and strategies for altering their shape. J. Anim. Sci. 42:1036-1051.

Gengler, N., A. Tijani, and G. R. Wiggans. 1999. Iterative solutions of random regression models by sequential estimation of regression and effects on regression. Computational Cattle Breeding 1999 Workshop. Available: http://www.csc.fi/ttn/ccb99/.

Gilmour, A. R., B. R. Cullis, and S. J. Welham. 1999. ASREML Reference Manual. Available: fttp://ftp.res.bbrsc.ac.uk/pub/aar/. Accessed Nov. 15, 1999.
Gregory, K. E., D. B. Laster, L. V. Cundiff, G. M. Smith, and R. M. Koch. 1979. Characterization of biological types of cattle-Cycle III: II. Growth rate and puberty traits. J. Anim. Sci. 49:461-471.

Henderson, C. R., Jr. 1982. Analysis of covariance in the mixed model: Higher-level, nonhomogeneous, and random regression. Biometrics 38:623-640.

Jamrozik, J., and L. R. Schaeffer. 1997. Estimates of genetic parameters for test-day model with random regression for yield traits of first lactating Holsteins. J. Dairy Sci. 80:762-770.

Jennrich, R. I., and M. D. Schluchter. 1986. Unbalanced repeatedmeasures models with structured covariance matrices. Biometrics 42:805-820.

Jones, H. E., I. M. S. White, and S. Brotherstone. 1999. Genetic evaluation of Holstein Friesian sires for daughter conditionscore changes using a random regression model. Anim. Sci. 68:467-475.

Kirkpatrick, M., and N. Heckman. 1989. A quantitative genetic model for growth, shape, reaction norms, and other infinite-dimensional characters. J. Math. Biol. 27:429-450.

Kirkpatrick, M., D. Lofsvold, and M. Bulmer. 1990. Analysis of the inheritance and evolution of growth trajectories. Genetics 124:979-993.

Kirkpatrick, M., W. G. Hill, and R. Thompson. 1994. Estimating the covariance structure of traits during growth and aging, illustrated with lactation in dairy cattle. Genet. Res. Camb. 64:57-69.

Koenen, E. P., and R. F. Veerkamp. 1998. Genetic covariance functions for live weight, condition score, and dry matter intake of lactating Holstein-Friesian heifers. Livest. Prod. Sci. 57:67-77.

Koenen, E. P. C., A. F. Groen, and N. Gengler. 1999. Phenotypic variation in live weight and live-weight changes of lactation Holstein-Friesian cows. Anim. Sci. 68:109-114.

Laird, N. M., and J. H. Ware. 1982. Random-effects model for longitudinal data. Biometrics 38:963-974.

Laster, D. B., G. M. Smith, and K. E. Gregory. 1976. Characterization of biological types of cattle: IV. Postweaning growth and puberty of heifers. J. Anim. Sci. 43:63-70.

Laster, D. B., G. M. Smith, L. V. Cundiff, and K. E. Gregory. 1979. Characterization of biological types of cattle: II. Postweaning growth and puberty of heifers. J. Anim. Sci. 48:500-508.

Littell, R. C., G. A. Milliken, W. W. Stroup, and R. D. Wolfinger. 1996. SAS System for Mixed Models. SAS Institute Inc., Cary, NC.

Meyer, K. 1995. Estimates of genetic parameters for mature weight of Australian beef cows and its relationship to early growth and skeletal measures. Livest. Prod. Sci. 44:125-137.

Meyer, K. 1998a. Estimating covariance functions for longitudinal data using a random regression model. Genet. Sel. Evol. 30:221-240.

Meyer, K. 1998b. "DxMRR"-A program to estimate covariance functions for longitudinal data by Restricted Maximum Likelihood. Proc. 6th World Cong. Genet. Appl. Livest. Prod., Armidale, Australia 27:465-466.

Meyer, K. 1998c. Modeling "repeated" records: Covariance functions and random regression models to analyze animal breeding data. Proc. 6th World Cong. Genet. Appl. Livest. Prod., Armidale, Australia 27:517-520.

Meyer, K. 1998d. DFREML, version 3.0 B, Users Notes. Available: ftp://metz.une.edu.au/pub/agbu/DFREML. Accessed Sept. 30, 1999.

Meyer, K. 1999. Estimates of genetic and phenotypic covariance functions for postweaning growth and mature weight of beef cows. J. Anim. Breed. Genet. 116:181-205.

Meyer, K. 2000. Random regression to model phenotypic variation in monthly weights of Australian beef cows. Livest. Prod. Sci. 65:19-38.

Meyer, K. 2001. Estimates of direct and maternal covariance functions for growth of Australian beef calves from birth to weaning. Genet. Sel. Evol. 33:1-28.

Meyer, K., and W. G. Hill. 1997. Estimation of genetic and phenotypic covariance functions for longitudinal or 'repeated' records by restricted maximum likelihood. Livest. Prod. Sci. 47:185-200. 
Rawlings, J. O., S. G. Pantula, and D. A. Dickey. 1998. Applied Regression Analysis: A Research Tool. 2nd ed. Springer Texts in Statistics. Springer-Verlag, Inc., New York.

Sandland, R. L., and C. A. McGilchrist. 1979. Stochastic growth curve analysis. Biometrics 35:255-271.

Schaeffer, L. R. 1997. Random regression in animal breeding. Course notes. Centre for Genetic Improvement of Livestock, CGIL, Guelph, Canada. Available: http://www.aps.uoguelph.ca/cgil/ pub/notes/notes.html. Accessed May 24, 2000.

Schaeffer, L. R. 1998. Random regression models. Ph.D. Course notes. Wageningen Institute of Animal Science, Wageningen, July 13$17,1998$.

Schaeffer, L. R., and J. C. M. Dekkers. 1994. Random regression in animal models for test-day production in dairy cattle. Proc. 5th World Cong. Genet. Appl. Livest. Prod., Guelph, Canada 18:443-446.
Thallman, R. M., L. V. Cundiff, K. E. Gregory, and R. M. Koch. 1999. Germplasm evaluation in beef cattle-Cycle IV: Postweaning growth and puberty of heifers. J. Anim. Sci. 77:2651-2659.

Thompson, W. J. 1997. Atlas for Computing Mathematical Functions: An Illustrated Guide for Practitioners with Programs in Fortran 90 and Mathematica. Wiley-Interscience, John Wiley, New York.

van der Werf, J. H. J., M. E. Goddard, and K. Meyer. 1998. The use of covariance functions and random regression for genetic evaluation of milk production. J. Dairy Sci. 81:3300-3308.

Varona, L., C. Moreno, L. A. Garcia-Cortes, and J. Altarriba. 1997. Multiple trait genetic analysis of underlying biological variables of production functions. Livest. Prod. Sci. 47:201-210.

Veerkamp, R. F., and R. Thompson. 1999. A covariance function for feed intake, live weight, and milk yield estimated using a random regression model. J. Dairy Sci. 82:1565-1573. 